\title{
Extract and Characterization of Starch from White Lupine Seed
}

\author{
Biruk Gedif Worku* \\ Ethiopian Institute of Textile and Fashion Technology (EiTEX), Ethiopia
}

*Corresponding author: Biruk Gedif Worku, Ethiopian Institute of Textile and Fashion Technology (EiTEX), Bahir Dar University, Bahir Dar, Ethiopia.

Received Date: September 25, 2020

Published Date: October 13, 2020

\begin{abstract}
The textile industry is one of the most important sectors in Ethiopia and has grown from year to year. The extraction and processing of starch from different resources are one of the most important agro industries in the world. Starch is a product commonly used in textile industries as a sizing agent and is mainly sourced from food crops. Those food crops are mostly edible by human beings. Therefore, alternative starch sources of materials are required. This research focused on extracted starch from white lupine seed which is not edible. Two extraction methods are used namely cold and hot steeping. From those cold steeping is much better than hot to get a quality starch which is comparable with the existing starch in the market like maize, white, etc. starches. After applying the extracted whit lupine starch in textile sizing, the tensile strength of warp yarn was not a significant difference. After sizing using extracted white lupine starch which is a hot and cold steeping method the average tensile strength was $320.9 \mathrm{cN}$ and $338.3 \mathrm{cN}$ respectively and the average elongation of yarn was $4.27 \%$ and $4.21 \%$ respectively achieved. The size pick-up $\%$ warp yarn in the case of hot and cold steeping is 10.64 and 14.85 respectively was achieved.
\end{abstract}

Keywords: Starch; Extraction; Textile; Sizing; White lupine seed

\section{Introduction}

The textile industry is one of the most important sectors in Ethiopia. Because the Ethiopian government has spearheaded the sector as one of the key priority sectors for which has contributed to the multiple aspects towards the economy of Ethiopia such as, investment, occupation and export. This is supported by the creation of various industry policies and incentives to attract foreign direct investors [1-3].

The textile industry mainly three basic sections those are spinning process, weaving and finishing. Under weaving, the sizing process is the heart of its. Sizing in weaving production serves to protect the warp yarns during the weaving process. Protective sizing agents help the yarn to withstand high mechanical stress during weaving. Starch material is one of the most important materials in textile industries to develop textile capability (strength, elasticity and surface strength) reduce friction in the weaving process and improve the feel and appearance of the fabric. They do this by improving the wear resistance of the warp threads and by reducing fiber abrasion. This prevents yarn breakage during weaving and thus machinery downtime. Furthermore, sizing improves the appearance of the woven fabric [4-8].

The invention relates to the use of native chemically unmodified amylose-type starch as a sizing agent for natural and/or synthetic textile yarns and textile blended yarns as well as to a process for sizing textile yarns using these starch products. The invention furthermore relates to the use of chemically modified amylose-type starch as a sizing agent for natural and/or synthetic textile yarns and textile blended yarns as well as to a process for sizing textile yarns using chemically modified amylose-type starch products [9].

The sizing agent must adhere strongly to the fiber, and its film properties should be largely independent of the climatic conditions, 
especially atmospheric humidity, and be unaffected by fiber finishes and sizing additives. The elongation of the warp thread should not be reduced by the presence of the sizing agent $[8,10]$.

After the gray cloth has been woven, the task of the sizing agent is complete. As it would usually have a deleterious effect on subsequent finishing processes, it must be completely removed. Removal is simple in the case of cold-water-soluble sizing agents, but starch products that are insoluble in cold water require preliminary enzymatic or oxidative breakdown before the de-sizing stage. The removal of the sizing agent may pose special wastewater treatment problems in finishing plants.

The growth of synthetic fibers and the developments in weaving technology has accelerated the development of synthetic sizing agents. The sizing agent to be used must satisfy different requirements, such as good penetrativeness, good adhesiveness, good film-forming properties and the ability to form an elastic sizing film. A suitable sizing agent imparts to the sized yarn desirable properties, such as a high wear resistance (abrasion resistance), a high weaving efficiency and good washing-out properties of the woven textile product [11-13].

The most important sizing agents are potato, maize, and tapioca starches. Wheat, rice, and sago starches are also used. The characteristic properties of these starches are determined by the amylose/amylopectin ratio, the degree of polymerization of these two constituents, and the size and fine structure of the starch grain. These parameters determine the swelling and solution behavior, and also the properties of the film $[6,8,14]$.

Natural starch is insoluble in cold water because of the hydrogen bonds linking parallel polymer chains. The starch is brought into "solution" by heating. The starch grains first absorb water until the swelling is at its maximum. Above a certain temperature, characteristic for each type of starch and known as the gelatinization temperature, the starch grains burst and form a gel. The viscosity increases to a maximum and then decreases asymptotically to a limiting value as the solubilized polymer molecules disperse. Complete solubilization of the individual molecules of a starch grain only occurs above $100{ }^{\circ} \mathrm{C}$. The viscosity value is important in size application, as it has a considerable effect on the amount of liquor pickup $[15,16]$.

Now, natural and manmade starch materials are used as a sizing agent in the textile application for increasing the yarn strength. Among these maize starch from natural origin is widely used for this application which is a common edible food by human beings. Because of its wide application, still there is a shortage of starch in the market. Therefore, extraction and characterization of starch from different sources is a great concern.

This research work focused on the extraction of starch from lupine which is not commonly used as food and has a lower cost to supplement the existing costly starch-based products in the coun- try, specifically for textile industries.

\section{Materials and Methods}

\section{Materials, equipment's and chemicals}

Warp yarn, white lupine (lupines Albus) seed, FTIR machine, Filter paper (polyester fabric), Beaker, Stove, Thermometer, litmus paper (Ph meter), Dryer, Laboratory Sizing Machine, balance, Portable yarn strength tester (single yarn strength tester), Wet milling machine, high- speed Stirrer and abrasion tester are required. Additionally, chemicals like iodine solution, sodium hydrosulphide are used as anti-oxidizing agents during extraction.

\section{Methods}

For this research, it was used two extraction methods, hot steeping and cold steeping processes. Generally,

Cleaning: The white lupine seed from stones, cobs, dust particles and foreign material was done

Steeping: Well-conducted steeping is an important prerequisite for high yield and good starch quality. At first, the purified white lupine kernels are transferred into a tank containing steep water. This step is conducted at $50{ }^{\circ} \mathrm{C}$ and lasts about 24 to 36 hours. Steeping tanks are commonly series- connected and operated by the counter flow principle. For optimal steeping conditions, steep- water is kept at $\mathrm{pH} 4$ by the addition of sulphuric acid or hydrochloric acid and treated with Sulphur dioxide. These conditions guarantee optimal water absorption of the lupine kernel, controlled fermentation by lactic acid bacteria and loosening of the protein matrix. At the same time, steep water causes the softening of the kernels and the release of soluble. Growth of lactic acid bacteria suppresses unwanted microorganisms such as yeasts, molds and other bacteria. During steeping the size of kernels nearly doubles and the water content increases from $15 \%$ up to $45 \%$.

Fine grinding and extraction: The germ removal step is followed by fine grinding in an impact mill to completely disrupt the cells of the endosperm and release the starch granules. The resulting suspension is led over bend green cascades for separation from fiber and other maize components. The starch milk, which contains the protein fraction, the so-called gluten, passes through. The bend screen cascades are connected in series. For complete washing out of the starch and separation of the fibers, they are operated by the counterflow principle. Additionally, washing water is added to the last process stage.

Starch refining: The starch milk, which still contains approximately a minimum amount of protein and fibers after separation, is then refined in a multi-step cyclone plant. The last stage of the multi-step cyclone plant is the only step of the wet milling process where freshwater is added.

Dehydration and drying: The refined starch milk, having a water content of approximately $65 \%$, is dehydrated in peeler centrifuges to a residual water content of about $40 \%$. The layer of the 
filter cake is colored yellow and contains high amounts of protein. It is reintroduced into the process. Pure starch is finally dried.

The two types of extraction methods are:
1. The hot steeping method is the process of socking the raw material by hot water (Figure 1).

2. The cold steeping method is a process of socking the raw material by the cold water (Figures 2-4).

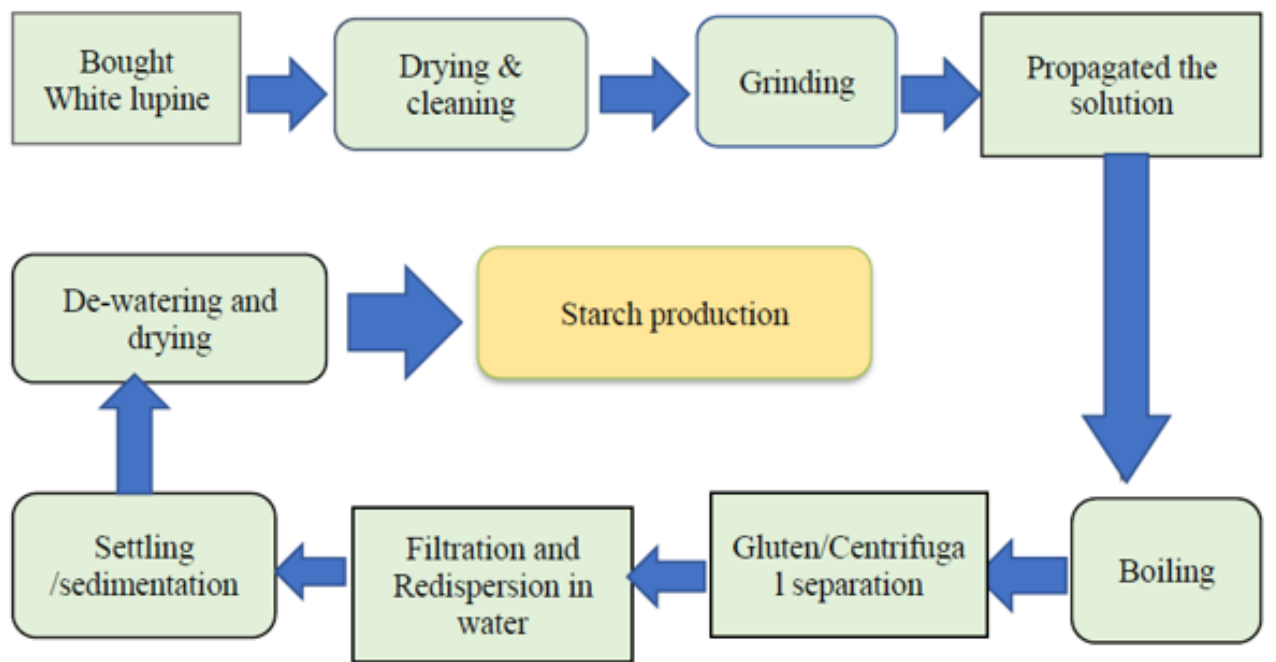

Figure 1: Hot steeping extraction processes.
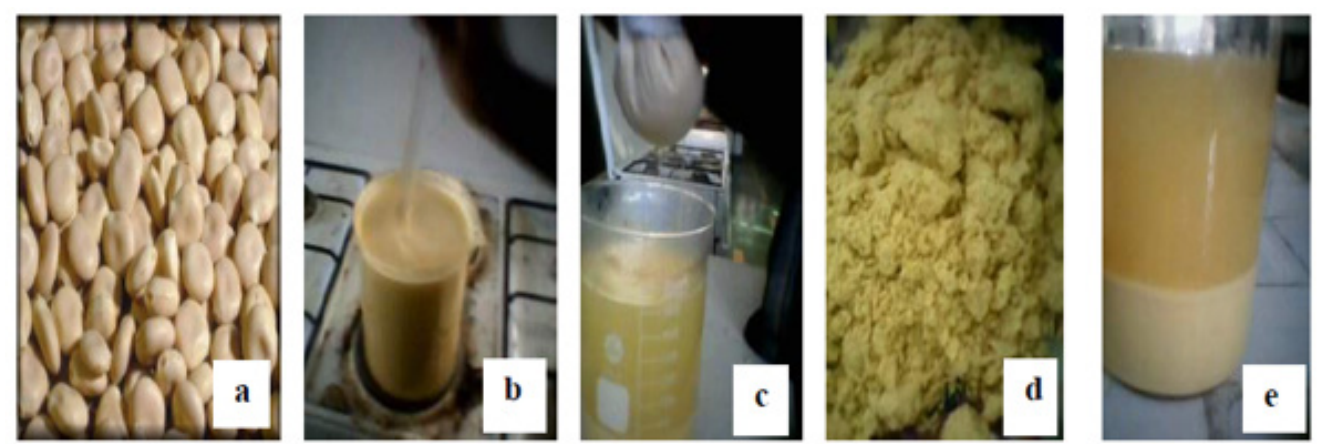

Figure 2: Hot steeping extraction processes (a) white lupine raw material (b)boiling and stirring (c) filtration (d)waste or fiber (e)settling \& sedimentation.

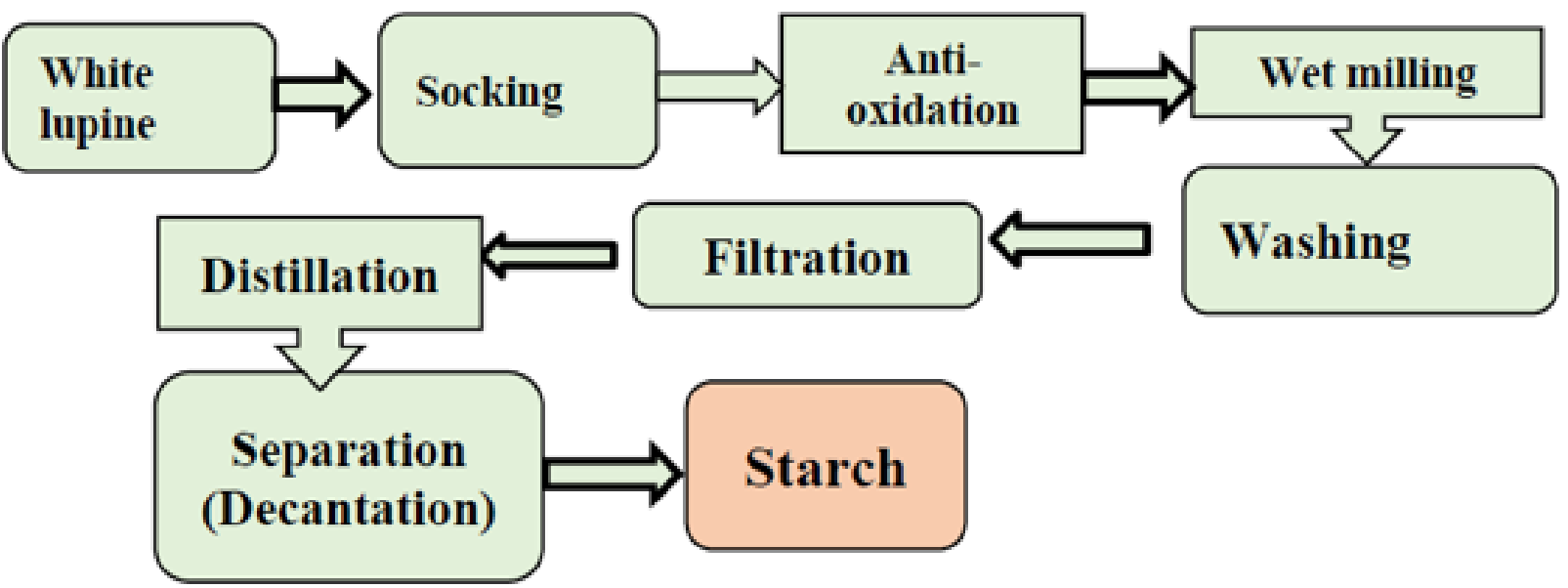

Figure 3: Cold steeping extraction processes. 

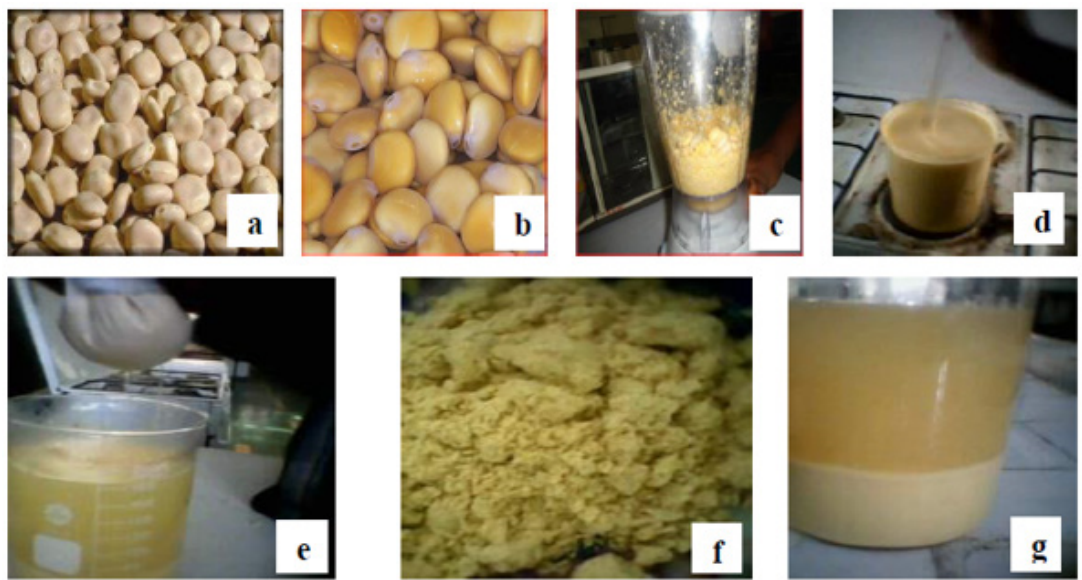

Figure 4: Cold steeping extraction processes (a) raw material (b) socking and anti-oxidation (c) wet milling (d) solution and string (e) filtration (f) white lupine fiber waste $(\mathrm{g})$ distillation after that decantation or separation and finally starch was gotten.

\section{Starch characterization}

Functional group analysis: The chemical structure of the sample was analyzed by a Spectrum PerkinElmer. This analysis was done for the identification of chemical compounds found in the sample through directing infrared rays towards the sample from which some of them are absorbed and the rest is passed (transmitted). The scan was done between $4000 \mathrm{~cm}^{-1}$ and $400 \mathrm{~cm}^{-1}$ averaged for each spectrum at intervals of $1 \mathrm{~cm}^{-1}$ with a resolution of $4 \mathrm{~cm}^{-1}$.

Iodine test: It is a test done to know whether the starch is present or absent. Once the starch and oil components are separated centrifugally, a drop of iodine solution is added on centrifugally separated sediments for approval of the existence of starch. The result is approved by looking at the color change seen after a drop of iodine solution $[17,18]$.

pH test: To evaluate the acidity and basicity of samples produced, PH test was carried out. The test was done by inserting litmus paper in a starch solution and looking color change of litmus paper $[17,18]$.

Sizing: The final product (extracted starch) was mixed with cold water and stirred using a metal rod for $5 \mathrm{~min}$. Additional water was added and the mixture was cooked for 45 minutes at $100{ }^{\circ} \mathrm{C}$. application of sizing past on 5 cons of 20 count warp yarn was carried out by using a laboratory scale sizing machine with a running speed of $20 \mathrm{~m} / \mathrm{min}$ having a cylinder drying temperature of $140{ }^{\circ} \mathrm{C}[18]$.

Strength regain and elongation at break: Initially, the samples were allowed to be conditioned for $24 \mathrm{hrs}$., and tensile properties of warp yarn before sizing and after sizing were evaluated by using a single yarn strength tester having $250 \mathrm{~mm}$ gauge length. The test was carried out by using ASTM D-2256 taking a breaking time of $20 \pm 2 \mathrm{~s}$. the test was repeated for five times and the mean was calculated [18].

\section{Results and Discussion}

\section{Starch characterization test}

Iodine Test: The iodine test is used to test for the presence of starch. Iodine solution - iodine dissolved in an aqueous solution of potassium iodide reacts with the starch producing a purple-black, blue, blue-black, brown, deep brown color. When we add iodine solution in our extracted starch solution, the color was changed to deep blue (blue-black) color which shows the presence of starch in the solution $[8,17]$ (Figure 5).

pH test: It is a measure of the acidic and basic property of the material in the starch solution media. The basic and acidic media is not recommended for sizing recipe preparation. The media of the sizing recipe must be neutral. When we measure the $\mathbf{p H}$ value of our extracted starch solution is 6.5-7 [8,19,20].

FT-IR analysis: Pure starch is a white, tasteless and odorless powder that is insoluble in cold water or alcohol. Starch contains two main components: amylose and amylopectin. Depending on the plant, starch generally contains 20 to $25 \%$ amylose and 75 to $80 \%$ amylopectin by weight. Their contents can be simply detected by measuring FTIR spectra.

As shown in Table 1, the FTIR spectral identified the key chemical compound existing in the white lupine starch as revealed in Figure 6 which shows the FTIR curve of the extracted whit lupine starch which confirms the presence of amylose and amylopectin. From the spectra, peaks in the range $3700-3600 \mathrm{~cm}^{-1}$; shows $\mathrm{O}-\mathrm{H}$ stretching; 3400 and $3300 \mathrm{~cm}^{-1} \mathrm{~N}-\mathrm{H}$ stretching; $2930 \mathrm{~cm}^{-1} \mathrm{C}-\mathrm{H}$ bond; 3000-2850 $\mathrm{cm}^{-1}$ range; $\mathrm{C}-\mathrm{H}$ aliphatic stretching; $1830-1650$ $\mathrm{cm}^{-1}$; carbonyl stretching, $\mathrm{C}=\mathrm{N}$ stretching at 1830-1650 $\mathrm{cm}^{-1}, 1080$ $\mathrm{cm}^{-1}$ to $1158 \mathrm{~cm}^{-1} \mathrm{C}-\mathrm{O}-\mathrm{H}$ bonds [21]. Using search-match software and a large database of standard compounds, all the above spectrum indicates the presence of starch and other constituent elements (Table 1). 

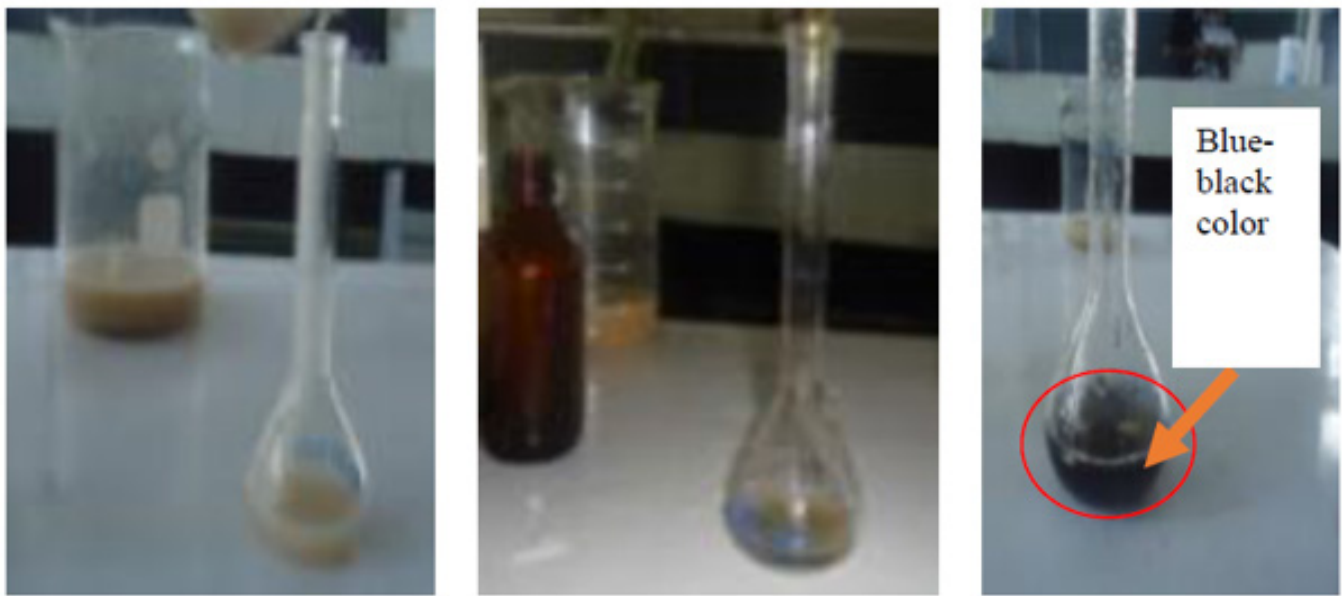

Figure 5: lodine test.

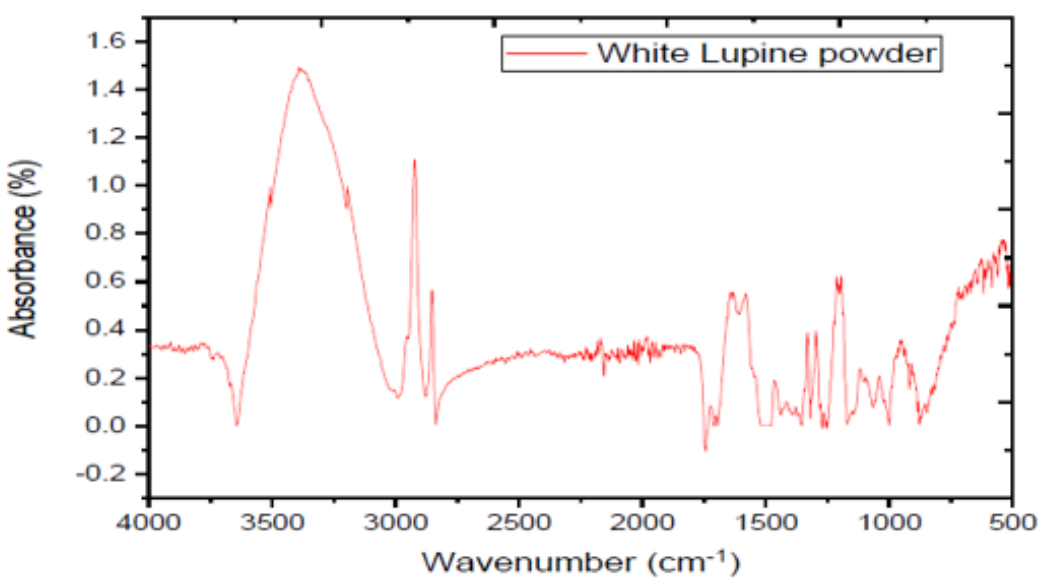

Figure 6: Extracted white lupine Starch FTIR spectrum

Table 1: Functional group.

\begin{tabular}{|c|c|c|c|c|}
\hline No. & Bond & Type of compound & Frequency range $\left(\mathrm{cm}^{-1}\right)$ & Intensity \\
\hline \multirow[t]{3}{*}{1} & \multirow[t]{3}{*}{$\mathrm{C}-\mathrm{H}$} & \multirow[t]{3}{*}{ Alkenes } & $3800-4000$ & Medium \\
\hline & & & $3010-3095$ & Medium \\
\hline & & & $675-995$ & Strong \\
\hline \multirow[t]{2}{*}{2} & \multirow[t]{2}{*}{$\mathrm{C}-\mathrm{H}$} & \multirow[t]{2}{*}{ Aromatic rings } & $3010-3100$ & Medium \\
\hline & & & $690-900$ & Strong \\
\hline \multirow[t]{4}{*}{3} & \multirow[t]{4}{*}{$\mathrm{O}-\mathrm{H}$} & Monomeric alcohol, phenols & $3590-3650$ & Variable \\
\hline & & Hydrogen bond alcohol, phenols & $3200-3600$ & Variable, sometimes broad \\
\hline & & monomeric carboxylic acids & $3500-3650$ & Medium \\
\hline & & Hydrogen bond carboxylic acid & $2500-2700$ & Broad \\
\hline 4 & $\mathrm{~N}-\mathrm{H}$ & Amine and amides & $3300-3500$ & Medium \\
\hline
\end{tabular}

These groups play an important role to strengthen the warp yarn and prevents the warp year from a high amount of breakage during the manufacturing of fabric. Because the warp year is highly exposed to variable stretching and high frictional force (Figure 6).
Application of the extracted white lupine starch in the textile sizing agent application Yarn strength regains and elongation test

Universal yarn strength tester machine, sized and un-sized yarn 
are required for testing yarn strength regain and elongation. Here machine adjustment, yarn preparation and testing are sequential activities done during analysis. Finally, size regains, standard deviation and coefficient of variance were evaluated using the following equation.

$$
S_{r}=\frac{S_{a s}-S_{b s}}{S_{b s}} \times 100 \%
$$

Where; $\mathrm{Sr}$ is yarn strength regains, $\mathrm{S}_{\text {as }}$ is the strength of yarn after sizing and $\mathrm{S}_{\mathrm{bs}}$ is the strength of yarn before sizing.

$$
\text { Standard Deviation }(\delta)=\frac{\sqrt{\sum(x i-m e a n)^{2}}}{n}
$$

$\%$ Coefficient of variance $(\% C V)=\frac{\delta}{\text { mean }} \mathrm{X} 100$

\begin{tabular}{|c|c|c|c|c|}
\hline \multirow[t]{2}{*}{ Test No. } & \multicolumn{2}{|c|}{ Strength $(\mathrm{cN})$} & \multicolumn{2}{|c|}{ Elongation (\%) } \\
\hline & Before sizing & After sizing & Before sizing & After sizing \\
\hline 1 & 301 & 304 & 6 & 4.4 \\
\hline 2 & 278 & 262 & 4 & 3.9 \\
\hline 3 & 260 & 378 & 5.4 & 3.2 \\
\hline 4 & 240 & 323 & 3.5 & 5 \\
\hline 5 & 286 & 356 & 4.3 & 5.2 \\
\hline 6 & 348 & 320 & 5.5 & 4.4 \\
\hline 7 & 270 & 314 & 4.7 & 4.1 \\
\hline 8 & 340 & 280 & 4 & 4.5 \\
\hline 9 & 307 & 324 & 3.7 & 3.5 \\
\hline 10 & 223 & 348 & 3.3 & 4.5 \\
\hline Average & 285.3 & 320.9 & 4.44 & 4.27 \\
\hline Standard deviation & 12.04 & 10.35 & 0.277 & 0.185 \\
\hline Coefficient of variance & 4.22 & 3.22 & 6.24 & 4.3 \\
\hline
\end{tabular}

\begin{tabular}{|c|c|c|c|c|}
\hline \multirow[t]{2}{*}{ Test No. } & \multicolumn{2}{|c|}{ Strength (cN) } & \multicolumn{2}{|c|}{ Elongation (\%) } \\
\hline & Before sizing & After sizing & Before sizing & After sizing \\
\hline 1 & 270 & 320 & 4.7 & 4 \\
\hline 2 & 265 & 378 & 5.5 & 4.5 \\
\hline 3 & 252 & 414 & 3.6 & 3.5 \\
\hline 4 & 320 & 281 & 4 & 3.6 \\
\hline 5 & 307 & 294 & 3.7 & 3.45 \\
\hline 6 & 300 & 308 & 5.6 & 4.5 \\
\hline 7 & 303 & 308 & 6.3 & 4.5 \\
\hline 8 & 223 & 358 & 3.3 & 4.8 \\
\hline 9 & 318 & 372 & 4 & 4.6 \\
\hline 10 & 378 & 350 & 6.4 & 4.7 \\
\hline Average & 293.6 & 338.3 & 4.71 & 4.21 \\
\hline
\end{tabular}

Table 3: Strength and elongation test results by using cold steeping extracted starch (20s). 


\begin{tabular}{|c|c|c|c|c|}
\hline 6 & 12.96 & 12.8 & 0.36 & 0.13 \\
\hline$\% \mathrm{cv}$ & 4.4 & 3.78 & 7.6 & 3.1 \\
\hline
\end{tabular}

Table 4: Strength and elongation test (take from Bahir Dar Textile Share Company (20s)) for comparison.

\begin{tabular}{|c|c|c|c|c|}
\hline \multirow{2}{*}{ Test No. } & \multicolumn{2}{|c|}{ Elongation (\%) } \\
\cline { 2 - 5 } & Before sizing & After sizing & Before sizing & After sizing \\
\hline 1 & 266 & 364 & 3.5 & 4 \\
\hline 2 & 220 & 340 & 3 & 4 \\
\hline 3 & 250 & 306 & 4 & 4.2 \\
\hline 4 & 262 & 364 & 4.5 & 3.5 \\
\hline 5 & 210 & 310 & 3.5 & 3.6 \\
\hline 6 & 210 & 348 & 4.5 & 4.3 \\
\hline 7 & 200 & 350 & 4 & 3 \\
\hline 8 & 250 & 318 & 6 & 3 \\
\hline 9 & 230 & 270 & 4 & 3.8 \\
\hline Average & 245 & 290 & 4.5 & 3.7 \\
\hline 6 & 234.3 & 326 & 4.15 & 3 \\
\hline
\end{tabular}

Table 5: Pick-up test.

\begin{tabular}{|c|c|c|c|c|c|c|}
\hline \multirow[b]{2}{*}{ No. test } & \multicolumn{2}{|c|}{ Hot steeping } & \multirow[b]{2}{*}{ Pick up (\%) } & \multicolumn{2}{|c|}{ Cold steeping } & \multirow[b]{2}{*}{ Pick up (\%) } \\
\hline & Before sizing(gm.) & After sizing (gm.) & & Before sizing & After sizing & \\
\hline 1 & 0.47 & 0.52 & \multirow{6}{*}{10.64} & $0.47 \mathrm{gm}$ & $0.54 \mathrm{gm}$ & \multirow{6}{*}{14.85} \\
\hline 2 & 0.49 & 0.55 & & 0.49 & 0.57 & \\
\hline 3 & 0.45 & 0.52 & & 0.45 & 0.55 & \\
\hline 4 & 0.48 & 0.51 & & 0.48 & 0.56 & \\
\hline 5 & 0.46 & 0.53 & & 0.46 & 0.54 & \\
\hline Average & 0.47 & 0.526 & & 0.47 & 0.552 & \\
\hline
\end{tabular}

\section{Pick up test}

$\%$ Size pick $u p=\frac{\text { weight of sized warp yarn-the weight of unsized warp }}{\text { weight of sized warp yarn }} \mathrm{X} 100$

The yarn has good size pick up, so it is enhanced by its strength to use for the resistance of different weaving motion (Table 5).

\section{Conclusion}

In this research, it was used two extraction methods namely cold and hot steeping extractions. From those cold steeping is much better than hot to get a quality starch which is comparable with the existing starch in the market like maize, white, etc. starches. After applying the extracted whit lupine starch in textile sizing, the tensile strength of warp yarn was not a significant difference. After sizing using extracted white lupine starch which are a hot and cold steeping method the average tensile strength was $320.9 \mathrm{cN}$ and $338.3 \mathrm{cN}$ respectively and the average elongation of yarn was 4.27 $\%$ and $4.21 \%$ respectively achieved. The size pick-up \% warp yarn in case of hot and cold steeping is 10.64 and 14.85 respectively was achieved.

In these regards, it can use white lupine starch in textile industries as a sizing agent and at the same time, the farmer can get a benefit.

\section{Acknowledgement}

Research project was sponsored by Ethiopian Institute of Textile and Fashion Technology.

\section{Conflict of Interest}

Author declare no conflict of interest.

\section{References}

1. van der Pols D (2015) Business opportunity report Ethiopia textile \& apparel industry Commissioned by Netherlands Embassy in Addis Abeba CBI and Nash international BV.

2. Wagaye BT, Walle GA (2018) Overview of Ethiopian Textile Industry. Journal of Textiles and Polymers 6(2): 117-120.

3. Staritz CL, Plank, Morris M (2016) Global Value Chains, Industrial Policy, and Sustainable Development-Ethiopia's Apparel Export Sector. International Centre for Trade and Development. 
4. Radley J (1976) The textile industry, in Industrial uses of starch and its derivatives. Springer pp. 149-197.

5. Kennedy JF, Cabalda VM, White CA (1988) Enzymic starch utilization and genetic engineering. Trends in Biotechnology 6(8): 184-189.

6. Grommers HE, van der Krogt DA (2009) Potato starch: production, modifications and uses. Starch, ( ${ }^{\text {rd }}$ edn), Elsevier, pp. 511-539.

7. Srinivas $T$ (2007) Industrial demand for cassava starch in India. Starch 59(10): 477-481.

8. Zhang S, Li Z, Lin L, Zhang L, Wei C (2019) Starch Components, Starch Properties and Appearance Quality of Opaque Kernels from Rice Mutants. Molecules 24(24): 4580.

9. Porter RA, Self JM (1995) Composition for sizing textiles and process using same. Google Patents.

10. Schlüter K (2000) Textile auxiliaries, 3. sizing agents. Ullmann's Encyclopedia of Industrial Chemistry.

11. Goswami BC, Anandjiwala RD, Hall D (2004) Textile sizing. CRC press, USA.

12. Hebeish A, Abdel-Rahman A, El-Hilw Z, Hashem M (2005) Cationized starch derived from pre-oxidized starch for textile sizing and printing. Starch 57(12): 616-623.
13. Gagliardi DD, Gruntfest IG (1950) Creasing and creaseproofing of textiles. Textile Research Journal 20(3): 180-188.

14. Kraak A (1992) Industrial applications of potato starch products. Industrial Crops and Products 1(2-4): 107-112.

15. Schopke H (2007) Amylose Starch Products as Sizing Agents for Textile Yarns. Google Patents.

16. Singleton J (2013) World Textile Industry. Routledge, USA.

17. Naguleswaran S (2013) Starch morphological and molecular structural relations to amylolysis.

18. Haile L (2020) Extraction and Characterization of Starch from Butula Lenta Plant. Journal of Textile Science \& Fashion Technology 6(4): 1-6.

19. Williams ST, Flowers TH (1978) The influence of pH on starch hydrolysis by neutrophilic and acidophilic streptomycetes. Microbios 20(80): 99106.

20. Ye F, Miao M, Jiang B, Campanella OH, Jin Z, et al. (2017) Elucidation of stabilizing oil-in-water Pickering emulsion with different modified maize starch-based nanoparticles. Food chemistry 229: 152-158.

21. Silverstein RM, Bassler GC (1962) Spectrometric identification of organic compounds. Journal of Chemical Education 39(11): 546. 